\title{
A Política de Pós-Graduação em Direito no Brasil e o impacto na produção acadêmico-científica: Uma observação sistêmica ${ }^{1}$
}

\section{The Postgraduate Policy in Law in Brazil and the impact on academic-scientific production: A systemic observation}

Giselle Marie Krepsky²

\section{Resumo:}

Este artigo trata da relação entre os Sistemas da Ciência, do Direito e da Política com intuito de verificar as interferências intersistêmicas na produção do conhecimento acadêmico-científico sobre o Direito. O objetivo da pesquisa foi observar como as Políticas Públicas das organizações que orientam a pesquisa jurídica no Brasil podem interferir nas produções acadêmico-científicas. A partir da teoria sistêmica de Niklas Luhmann a pesquisa demonstrou que há incongruências entre os documentos que organizam os Programas de Pós-Graduação Stricto Sensu em Direito que podem comprometer a qualidade da observação científica limitando a prestação do Sistema da Ciência para a sociedade.

Palavras-Chave: Pós-Graduação em Direito; Políticas Públicas; Produção acadêmicocientífica; Organizações; Sistema da Ciência.

\section{Abstract:}

This article deals with the relation between the Systems of Science, Law and Politics in order to verify the intersystemic interference in the production of academic-

\footnotetext{
${ }^{1}$ Produção científica com auxílio do Edital CAPES no 002/2013 - DINTER UNISINOS/FURB.

2 Doutora em Direito pela Universidade do Vale do Rio dos Sinos (UNISINOS). Mestre em Educação (Ensino Jurídico). Especialista em Direito Administrativo. Pesquisadora do Grupo de Pesquisas CNPq: Direitos Fundamentais, Cidadania e Novos Direitos, atuando nas linhas: Sistema Jurídico e Produção do Conhecimento e Diferenciação, Complexidade e Risco. Professora titular do Curso de Direito da Universidade Regional de Blumenau (FURB), Blumenau, Santa Catarina, Brasil. Rua Antônio da Veiga, 140, Itoupava Seca. CEP 89030903. (47) 3321-0239. E-mail: gkrepsky@ furb.br.
} 
scientific knowledge about Law. The objective of the research was to observe how the Public Policies of organizations that guide legal research in Brazil can interfere in the academic-scientific productions. From the systemic theory of Niklas Luhmann the research showed that there are inconsistencies between the documents that organize the Stricto Sensu Postgraduate Programs in Law that can implicate the quality of scientific observation limiting the provision of the Science System to society.

Keywords: Postgraduate in Law; Public Policies; Academic-scientific production about Law system; Organizations; Science system.

\section{INTRODUÇÃO}

Partindo-se do conceito de Sistema como “[...] uma diferença que se produz constantemente, a partir de um único tipo de operação" e que "A operação realiza o fato de reproduzir a diferença sistema/meio, na medida em que produz comunicação somente mediante comunicação" (LUHMANN, 2010a, p. 91, tradução nossa), esta comunicação só tem sentido específico em cada sistema. Um sistema só existe enquanto possível a diferenciação de seu meio, e, portanto, não pode existir sem um ambiente. Sendo assim, os Sistemas do Direito e da Ciência, como subsistemas ${ }^{3}$ da sociedade global, possuem funções, operações, estrutura e comunicações diferenciadas.

No contexto da complexificação social as relações entre Direito e Ciência têm se estreitado levando a acoplamentos importantes para as operações de cada um destes sistemas. Porém, as formas de observação da Ciência Jurídica (observação científica da autoobservação do Direito) bem como o seu estreitamento com a Dogmática Jurídica (autoobservação do Sistema do Direito) demonstram obstáculos estruturais para o surgimento de novas respostas aos problemas jurídicos contemporâneos.

Uma vez que para Luhmann a sociedade é, sobretudo, comunicação, urge observar como eventuais acoplamentos entre estes Sistemas podem interferir nas comunicações do Direito e da Ciência. Nesse tocante, a produção acadêmico-científica sobre o Direito é comunicação do Sistema da Ciência e é oriunda dos centros de produção científica, em especial das Universidades.

\footnotetext{
3 Apesar de Direito, Ciência, Educação, Economia, entre outros, serem considerados subsistemas parciais da sociedade global, para esta pesquisa eles foram referidos apenas como "Sistemas".
} 
As produções acadêmico-científicas ${ }^{4}$ sobre o Direito são observações privilegiadas das operações realizadas pelo sistema jurídico porquanto podem observar o que o próprio Direito e sua Dogmática ocultam da sua auto-observação. Isto poderia levar à possibilidade de prestação do Sistema da Ciência para a Dogmática e, ainda, uma observação do Sistema do Direito sobre o que se produz academicamente, sofisticando, assim, suas operações decisórias. O locus de produção acadêmico-científico sobre o Direito, como comunicação do Sistema da Ciência, ocorre, primordialmente, por meio dos seus Programas de Pós-Graduação Stricto Sensu, muito embora existam outros meios de comunicação.

Portanto, o tema desta pesquisa é a relação entre os Sistemas da Ciência, do Direito e da Política com intuito de observar as interferências intersistêmicas na produção do conhecimento acadêmico-científico sobre o Direito. Afinal, se a Dogmática precisa estar em consonância com o ambiente do Sistema do Direito e a Ciência constrói constantes comunicações a partir da observação sofisticada do Sistema do Direito, um dos problemas é a limitação da produção acadêmico-científica oriunda do direcionamento das políticas que se impõem aos órgãos de pesquisa, o que implica em interferências na comunicação da Ciência Jurídica e, por conseguinte, na sua capacidade de produzir irritações na Dogmática. Por isso, entender como as organizações orientam a pesquisa jurídica no Brasil a partir de suas diretrizes bem como os Programas de Pós-Graduação Stricto Sensu interferem nesta produção científica torna-se relevante. Para tal observação, elegeu-se a teoria dos sistemas de Niklas Luhmann. A partir de análise documental e de pesquisa bibliográfica construiu-se indutivamente o relato de pesquisa a seguir.

\section{O PAPEL DAS ORGANIZAÇÕES SOB UMA OBSERVAÇÃO SISTÊMICA}

A organização da pesquisa científica na área jurídica no Brasil está vinculada a organizações específicas que se estruturam, decidem e comunicam. Assim, Política,

\footnotetext{
${ }^{4}$ Do ponto de vista da teoria sistêmica, somente quando o código verdadeiro/falso usado pelo Sistema da Ciência orienta as seleções das diferenciações a partir das quais o mundo [do Direito] é observado, designado, descrito e explicado sob o código verdade/não verdade com auxílio dos programas que complementam seu código e comunicado por meio das publicações inerentes ao Sistema da Ciência, é que se pode afirmar que se trata de comunicação científica sobre o Direito. Cf. LUHMANN, Niklas. La Ciencia de la Sociedad. Trad. Silvia Pappe, B. Erker e Luis Segura sob Coord. Javier Nafarrate. México: Universidad Iberoamericana, 1996. p. $94-$ 95.
} 
Administração e Organização são categorias imprescindíveis para a observação das organizações decisórias que influenciam direta ou indiretamente sobre as particularidades da pesquisa sobre o Direito bem como nas suas publicações que podem ser consideradas como as mais sofisticadas: as teses.

\begin{abstract}
As organizações constituem um fenômeno característico da sociedade moderna, que se relacionam com a sociedade de tal maneira, que constituem um meio através do qual os distintos subsistemas funcionais da sociedade buscam soluções específicas aos problemas que a sociedade enfrenta. [...] A organização, [é] caracterizada pela capacidade de condicionar a pertinência. Para ingressar em uma organização como membro - e para permanecer como tal - uma pessoa deve satisfazer as condições estabelecidas pelo sistema organizacional. [...] As organizações tem proliferado, especializando-se em temas específicos. (MANSILLA, 2004, p. 21-27, tradução nossa).
\end{abstract}

As relações destas organizações apresentam-se de forma a reduzir a complexidade social, tal qual ocorre com os demais sistemas ou subsistemas sociais, porém, nem por isso, deixam de evidenciar a complexidade interna com as quais têm que operar e decidir. Isso, sem dúvida, afeta a evolução da produção científica brasileira.

Nesse tocante, basta observar que as Universidades, típicas organizações de acordo com a teoria sistêmica, absorvem funções duplas porquanto inerentes aos Sistemas da Educação e da Ciência. Isso ocorre, pois as atividades de ensino e pesquisa seguem por vezes imbricadas e muitas vezes operacionalizam-se a partir de pessoas que as executam concomitantemente. Sabe-se que é a partir dos Programas de Pós-Graduação, que pertencem à estrutura das Universidades que emanam as teses produzidas sobre o Direito. Por outro lado, as orientações, regulamentações e principais vinculações para aprovação e permanência de um Programa de Pós-Graduação se dão pela validação e controle da Coordenação de Aperfeiçoamento de Pessoal de Nível Superior (CAPES), que, por sua vez, está vinculada ao Ministério da Educação (MEC), inerente ao Sistema da Política ${ }^{5}$ e não ao da Ciência e Tecnologia. Isso precisa ser observado levando-se em consideração a existência ou não de acoplamentos entre os sistemas da Ciência, da Educação, da Política e, inclusive do Direito, porquanto necessário para legitimar as decisões que se pretendem vinculantes para a sociedade, bem como entre as diversas organizações envolvidas na produção de pesquisa no Brasil.

\footnotetext{
${ }^{5}$ Ainda que se possa considerar esta organização acoplada com o Sistema da Educação.
} 
Portanto, a organização mostra-se relevante para a observação em questão e, para Luhmann (2010b, p. 68, tradução nossa) deve ser considerada a partir de "[...] uma definição circular: uma organização é um sistema que se produz a si mesma como organização." A organização pode ser considerada um tipo de sistema social que se constitui a partir de regras que as tornam reconhecíveis, ou seja, ser o que são em diferença a outros sistemas e que permitem a especificação das próprias estruturas. Estas regras são primordialmente as que indicam pertinência que podem ser determinadas mediante a seleção de pessoal e de uma lista interna, visto que nem todos podem fazer parte de uma organização formal. (CORSI, ESPOSITO, BARALDI, 1996).

Para Luhmann (1996), as organizações assumem um papel importante praticamente em todos os sistemas e são os únicos sistemas sociais que são, de fato, os que comunicam ao exterior os resultados que são elaborados no seu interior, tal qual funcionam os Tribunais para o Sistema do Direito. Então, têm-se organizações econômicas, estatais, organizações políticas, escolares, científicas, jurídicas, legislativas e assim por diante. Todavia, é preciso entender que tanto as organizações quanto os sistemas ao qual pertencem são autopoiéticos sendo que as organizações se voltam para as operações que lhe são próprias, mas atendendo ao primado do sistema de pertinência. Isso quer dizer que nenhum sistema conseguirá alcançar a sua própria unidade a partir de suas organizações. E, nenhuma organização pode atrair para si todas as operações do sistema executando as operações como se fossem suas próprias. (LUHMANN, 2007).

O papel das organizações na pesquisa e seus enlaces ou acoplamentos com outras organizações de outros sistemas são deveras relevantes para a concretização da Ciência. Nesse sentido, elas não podem ser subestimadas na sua capacidade de repercussão. Nas organizações científicas, além dos programas (teorias e métodos) nortearem as suas operações de forma bastante rígida, devem ser levadas em consideração outras características igualmente pouco flexíveis e que podem ser analisadas sob as questões ditas "burocráticas". Então, as repercussões das organizações se estendem à influência que podem exercer na seletividade ou não reduzindo ou aumentando a influência da própria Ciência na investigação, propiciando interferência externa com decisões determinantes, como por exemplo, a partir do Sistema da Política. 
A importância da organização no sistema da Ciência é tamanha que se exige dela muito mais do que uma relação direta com a produção do conhecimento. A partir da necessidade de sua auto-administração, da participação democrática das decisões e outras coisas que são similares a estas se tornam supervalorizadas de forma a afetar o resultado das investigações. Então, ao invés de investigar, podem existir outros méritos no âmbito das organizações científicas, como cargos de gerência, supervisão de projetos, coordenadores e vice-coordenadores, ministro, secretários, que, embora colaborem com a função social da ciência, muitas vezes distanciam-se ou nem mesmo exercem a função de investigadores. Isso é bem comum nas Universidades ou em grandes institutos de pesquisa, os quais acabam criando cargos ou atividades cujos funcionários exercem a função diretiva, mas na prática já não mais influenciam na investigação científica propriamente dita ou nas operações posteriores internas ao Sistema Científico. (LUHMANN, 1996).

Outra situação que Luhmann (1996) chama de anomalia nas Universidades e que afeta a função do Sistema da Ciência é o fato de que elas têm que mostrar um excelente rendimento tanto no que se refere à pesquisa, quanto à educação. Aliás, não se lhes exige apenas estas funções, mas, além disso, a extensão, conforme preceitua a Constituição Federal brasileira (CF) já que "As universidades gozam de autonomia didático-científica, administrativa e de gestão financeira e patrimonial, e obedecerão ao princípio de indissociabilidade entre ensino, pesquisa e extensão." (BRASIL, 1988, art. 207)

Isso vem ao encontro da anomalia referida pelo autor, já que mostra um acoplamento direto da docência com a investigação científica, que, se levada ao pé da letra, pode conduzir a uma séria falta de rendimento nos dois campos de atuação. Portanto:

Entidades complexas como as universidades produzem conhecimentos mediante a
investigação científica, capacitam recursos humanos para o mercado, formam as
elites políticas, desenvolvem pensamento crítico e inovador, proporcionam espaços
para a expressão e desenvolvimento juvenil, e também, se é o caso, devem se
autofinanciar ou diretamente lucrar para seus investidores. Por certo, a variedade
interna admitida por este tipo de organização repercute no grau de complexidade de
suas estruturas e as adentra em dinâmicas que pressionam por sua diferenciação
interna - campus, faculdades, institutos, centros, departamentos, escolas, etc. - ou as
dispõem para a formação de organizações mais especializadas. (ARNOLD-
CATHALIFAUD, 2014, p.33, tradução nossa).

Não bastassem todas essas influências sobre as publicações e sobre os êxitos científicos das investigações, destaca-se que as organizações ainda podem interferir na forma 
com a qual selecionam e até mesmo deformam a comunicação científica uma vez que existe uma multiplicidade de organizações e sendo assim, há possibilidade de que os investigadores possam migrar de uma para outra, ou até mesmo conciliarem a permanência em várias delas ao mesmo tempo.

Então, para compreender-se o policontexto no qual está inserida a pesquisa jurídica no Brasil, parte-se inicialmente do que preceitua a CF quanto a tais organizações, uma vez que a Constituição é, sobretudo, a exteriorização suprema do acoplamento entre Direito e Política e explicita, notadamente, as diretrizes sob as quais o Sistema da Política intervém nas questões de pesquisa. Conforme prevê o artigo 24: "Compete à União, aos Estados e ao Distrito Federal legislar concorrentemente sobre: IX - educação, cultura, ensino, desporto, ciência, tecnologia, pesquisa, desenvolvimento e inovação;" Logo, as normas gerais no que se refere à ciência, tecnologia, pesquisa, educação e ensino ficarão ao encargo da União. Já no que se refere à competência material ou administrativa, o artigo 23 indica que: "É competência comum da União, dos Estados, do Distrito Federal e dos Municípios: [...] proporcionar os meios de acesso à cultura, à educação, à ciência, à tecnologia, à pesquisa e à inovação;" Estas regras foram incluídas no texto Constitucional a partir da Emenda $n^{\circ}$ 85/2015, portanto, muito recente e em consonância com a preocupação com o desenvolvimento das atividades científicas, tecnológicas e de inovação do país.

Ainda no âmbito das intenções do Estado, verifica-se no artigo 218 da CF que: "O Estado promoverá e incentivará o desenvolvimento científico, a pesquisa, a capacitação científica e tecnológica e a inovação.” Todavia, ressalta-se que a prioridade nesta seara se dá conforme o $\S 1^{\circ}$ e seguintes: "§ $1^{\circ}$ A pesquisa científica básica e tecnológica receberá tratamento prioritário do Estado, tendo em vista o bem público e o progresso da ciência, tecnologia e inovação." Igualmente incluído pela Emenda Constitucional (EC) no 85/2015, este parágrafo demonstra uma especial preocupação com o desenvolvimento econômico do país.

Segundo Kato (2012), essa preocupação e que tem ligação direta com os fomentos das organizações para pesquisa, indicam o quanto as pautas investigativas no campo da Ciência, Tecnologia e Inovação acabam centralizando a força produtiva para a qual o Estado tem canalizado esforços nos últimos anos. 


\section{ORGANIZAÇÃO DA PESQUISA CIENTÍFICA NO BRASIL E SUAS INTERFERÊNCIAS INTERSISTÊMICAS NA PRODUÇÃO DO CONHECIMENTO JURÍDICO}

Diante deste contexto, faz-se necessário observar as relações dos Programas de PósGraduação das Universidades e as demais organizações que exercem funções primárias em outros sistemas como o da Política. Entre estas organizações, encontram-se o Ministério da Educação (MEC), a Coordenação de Aperfeiçoamento de Pessoal de Nível Superior (CAPES), o Ministério da Ciência, Tecnologia, Inovações e Comunicações (MCTI) e o Conselho Nacional de Desenvolvimento Científico e Tecnológico (CNPq). ${ }^{6}$ A pesquisa concentrou-se nas principais interferências das duas primeiras organizações, em especial no que concerne à regulamentação e avaliação.

Para tanto, as primeiras observações devem ser construídas com base nas relações intersistêmicas entre Ciência e Política a partir das principais organizações no âmbito brasileiro, quais sejam: a CAPES, o CNPq e as Universidades a partir das quais as pesquisas mais sofisticadas no âmbito acadêmico são comunicadas sob a forma de teses. A CAPES está inserida no MEC, o CNPq no MCTI. Porém, as Universidades inserem-se tanto no MEC quanto no MCTI haja vista a gama de funções e finalidades as quais devem exercer, o que evidencia um acoplamento entre Ciência e o sistema da Política na organização da pesquisa acadêmico-científica.

Importante destacar que para Corsi, Esposito e Baraldi (1996), por sistema Político se entende o sistema cuja função é a de conduzir a sociedade por meio de decisões que sejam coletivamente vinculantes e, por isso, ele está estreitamente vinculado com a utilização do poder. É por meio deste poder que é possível a reprodução da comunicação política. Tal qual os demais sistemas, a Política é igualmente um sistema autopoiético, dotado de organizações. Seus processos comunicativos estão vinculados a uma auto-sensibilização, ou seja, ela se torna sensível aos problemas e tarefas com a qual se vincula com o entorno o que se reflete a

\footnotetext{
${ }^{6}$ Ressalta-se, todavia, que outras organizações transitam na periferia dos sistemas. São organizações que também exercem papel importante no direcionamento das pesquisas jurídicas no Brasil, ainda que não façam parte do Sistema Político, como as Associações de Pesquisadores. Exemplificativamente tem-se o Conselho Nacional de Pesquisa e Pós-Graduação em Direito (CONPEDI), Academia Brasileira de Direito Constitucional (ABDConst), Associação Brasileira de Pesquisadores em Sociologia do Direito (ABRASD), Rede de Estudos Empíricos em Direito (REED), Sociedade Brasileira para o Progresso da Ciência (SBPC), a Academia Brasileira de Ciências (ABC) entre tantas outras importantes que poderiam ser citadas.
} 
partir de temas específicos. (LUHMANN, 2002). Todavia, o sistema Político baseia-se em um tripé, ou seja, em uma distinção tridimensional sob a qual operam Política, Administração e Público. Em particular é no âmbito da Administração que se incorporam hierarquias e mandatos. Por isso, em sentido mais amplo ele utiliza o termo Administração para incluir o governo ou o executivo e o legislativo. (LUHMANN, 2002).

Assim, passa-se a descrever as competências dos referidos órgãos da Administração indireta a fim de demonstrar as suas interferências na organização da pesquisa no Brasil, em especial no que se refere à autonomia científica das Universidades estruturadas por meio de seus Programas de Pós-Graduação.

A CAPES é uma fundação do MEC cujo principal papel é a consolidação da PósGraduação Stricto Sensu nos níveis Mestrado e Doutorado em todos os estados da Federação. Suas principais atividades são estruturadas a partir das seguintes linhas de ação: a) avaliação da pós-graduação Stricto Sensu; b) acesso e divulgação da produção científica; c) investimentos na formação de recursos de alto nível no país e exterior; d) promoção da cooperação científica internacional; e) indução e fomento da formação inicial e continuada de professores para a educação básica nos formatos presencial e a distância. No que se refere à avaliação dos Programas, a CAPES utiliza seus diagnósticos e resultados para a formulação tanto de políticas para a Pós-Graduação quanto para a concessão de bolsas e auxílios financeiros para a pesquisa. Verifica-se que não só a avaliação é realizada pela CAPES, como também por meio dela há regulação e direcionamento por meio das Políticas Públicas para a pesquisa no país. Isto, sem sombra de dúvidas, indica que além de haver um acoplamento entre o sistema Político a partir do subsistema Administração e a Ciência, há também com o Direito, por meio do qual tais políticas tornam-se exigíveis.

Pois bem, as comunicações científicas são efetuadas no âmbito dos Programas de Pós-Graduação (Mestrados e Doutorados) para os quais são estabelecidas Políticas Públicas e de administração direcionadas por organizações como a CAPES. Os Doutorados, os que são relacionados com as produções de maior sofisticação científica, têm sua base conceitual estabelecida a partir do Parecer da Câmara de Ensino Superior (CESu) nº 977 de 1965, portanto, exarado há mais de cinco décadas.

No sentido de garantir a qualidade dos Mestrados e Doutorados existe uma série de órgãos e normativas que estabelecem critérios operacionais para dirigir e controlar sua 
implantação e desenvolvimento bem como a autorização, reconhecimento e renovação de reconhecimento destes Cursos que são obtidos por meio de acompanhamento periódico conforme as exigências estabelecidas pela Resolução do Conselho Nacional de Educação. A partir destas normativas verifica-se que, no que concerne ao funcionamento dos Programas de Pós-Graduação Stricto Sensu, há uma rede sofisticada e bastante articulada de órgãos pertinentes à grande organização da CAPES e que por sua vez são compostos ou dirigidos por pessoas que assumem os papéis a serem executados de acordo com a função do Sistema Político (subsistema Administração) ainda que em acoplamento com o Sistema da Ciência. Isso exige uma expertise para a condução de abertura, manutenção e articulação destes Cursos.

A representatividade científica perante estas organizações se dá especialmente pelas Coordenações de Área. Nesse sentido, em tese, há uma participação da comunidade científica nas deliberações tomadas pela Administração. De acordo com a CAPES, estes coordenadores são consultores que são designados para coordenar, planejar e executar atividades na sua respectiva área de conhecimento, durante três anos. Dentre estas atividades incluem-se as relativas à avaliação dos Programas de Pós-Graduação. Para ser um coordenador de área, o acadêmico deve ter notório conhecimento bem como experiência tanto no ensino como na orientação de pós-graduação, além de envolvimento com a pesquisa e com a inovação. Além destas funções, dezoito dos vinte e quatro membros do Conselho Técnico-Científico da Educação Superior são coordenadores de área indicados por seus pares a partir das grandes áreas de Conhecimento alocadas em Colégios. Este Conselho tem competência para deliberar em última instância sobre propostas de cursos novos e notas atribuídas na avaliação periódica dos programas de Pós-Graduação conforme o artigo 13 do Decreto nº 7.692/2012.

Mas a escolha dos coordenadores de área tem a participação do Conselho Superior da CAPES, que é órgão colegiado e deliberativo. De acordo com o artigo 12, XI do já referido decreto, o Conselho tem competência para "definir o processo e critérios de escolha dos coordenadores das áreas de avaliação de que trata o $\S 2^{\circ}$ do art. $3^{\circ}$ e encaminhar ao Presidente suas indicações por meio de listas tríplices.”. Segundo informações da CAPES, estas listas tríplices são definidas a partir da relação de nomes advindos de "ampla consulta ${ }^{7}$ feita aos

\footnotetext{
${ }^{7}$ A única passagem do Decreto que trata de uma consulta pública refere-se ao Conselho Técnico-Científico da Educação Básica que, de acordo com o inciso IV, terão até vinte representantes da sociedade civil escolhidos
} 
cursos ou Programas de pós-graduação e às associações e sociedades científicas e de pósgraduação.”

O Direito compreende uma das 48 áreas de Avaliação e Coordenação. O atual Coordenador é Gustavo Ferreira Santos da Universidade Federal de Pernambuco (UFPE), o Coordenador Adjunto é Antonio Gomes Moreira Maués da Universidade Federal da Paraíba (UFPA) e Gustavo Silveira Siqueira (UERJ) de Coordenador Adjunto de Mestrado Profissional. Ressalta-se que os Coordenadores atuais dos Mestrados Acadêmicos e Doutorados são ambos da região Nordeste e oriundos de Universidades Públicas porquanto pertencentes a Universidades Federais. Apesar de o processo de indicação ser democrático e participativo, ressalta-se que de todos os Cursos de Pós-Graduação em Direito, apenas em torno de $16 \%$ concentram-se na região nordeste. Veja-se que as regiões sul e sudeste reúnem quase $73 \%$ do total de Cursos, porém não estão representados nas Coordenações de área, limitando suas capacidades de interlocução científica no referido órgão.

A partir deste contexto legal e organizacional e aproximando-se dos Programas de Pós-graduação em Direito (PPGD’s) do Brasil, indispensável observar como se dá a aprovação e a avaliação de tais Cursos, posto que as grandes temáticas a serem investigadas sobre o Direito estão imbricadas tanto no que se refere à Política de Avaliação de Periódicos quanto dos Programas que são organizados por Áreas de Concentração e Linhas de Pesquisa.

Para a proposta de novos Cursos de Pós-Graduação em Direito que, depois de aprovados, serão avaliados numa escala numérica de 1 a 7 , sendo que permanecerão em funcionamento apenas os que obtiverem nota igual ou superior a 3, várias etapas devem ser observadas. Simplificadamente, as propostas percorrem as seguintes etapas: a) procedimentos Iniciais; b) avaliação da Proposta pela Comissão de Área; c) decisão pelo Conselho Técnico e Científico da Educação Superior - CTC-ES; d) divulgação dos resultados da avaliação; e) publicação no Diário Oficial da União.

Verifica-se que há uma participação direta tanto dos Conselhos Técnico-Científicos como do Conselho Nacional de Educação, que, ao final é o órgão que decidirá sobre a aprovação do novo Curso. De acordo com as orientações gerais da CAPES as propostas de

dentre profissionais de reconhecida competência em educação básica, observada a representatividade regional e por área de formação, quando possível e que, de acordo com o $\S 3^{\circ}$, os membros de que trata o inciso IV do caput serão designados pelo Presidente da CAPES, a partir de listas tríplices elaboradas pelo Conselho Superior, após consulta à sociedade civil, e terão mandato de três anos, admitida uma recondução. Cf. Artigo 10 do Decreto n ${ }^{\circ} 7.692 / 2012$. 
Cursos de Mestrado e Doutorado deverão se enquadrar em áreas básicas e em áreas de avaliação conforme a Portaria CAPES nº 90 de 29 de julho de 2015. Isso ocorre porque existem Cursos que, de acordo com a lista de recomendação, possuem área de Avaliação Direito, mas possuem Área Básica mais específica, como por exemplo: História do Direito, Teoria do Direito, Direito Público, entre outras. Todavia, além dos requisitos mais gerais e formais, o principal documento que orienta a abertura de novos Cursos dá-se pela Avaliação de Propostas de Cursos Novos (APCN). O Direito possui APCN-2017 (CAPES, 2016b) publicada em 18 de novembro de 2016 e que não destoa da APCN-2016 (CAPES, 2016a). Deste documento destacam-se alguns requisitos que influenciam diretamente na qualificação científica dos Cursos de Doutorado que interessam para este estudo, tais como:

1- "Não pode haver significativa diferença entre os cursos que já se encontram no sistema e os cursos novos." Ou seja, se o Programa já conta com Mestrado em determinada área, o Doutorado não pode ter um afastamento desta que já foi estabelecida, portanto, as teses, provavelmente situar-se-ão em temáticas similares às das dissertações, alterando-se critérios de profundidade científica e específicos de cada Curso.

2- "É necessário que tenha alcançado a nota 4 (quatro) na última avaliação." Portanto, somente poderão propor Curso de Doutorado os Programas que obtiverem nota no mínimo de 4 nos seus Cursos de Mestrado demonstrando a necessidade de uma consistência no que já se produz no referido Programa.

3- "É indispensável que a proposta contenha uma descrição detalhada do perfil do egresso a ser formado, correlacionando-o com a área de concentração, linhas de pesquisa, estrutura curricular e projetos de pesquisa propostos para o programa; [...] As linhas de pesquisa constituem a restrição temática, o recorte específico da área de concentração representado pela capacidade docente instalada no Programa. [...] A atividade de pesquisa representa a concretização desse recorte. Devem, portanto, cobrir de maneira coerente as dimensões fundamentais da área de concentração. Por isso mesmo, i) a atividade de pesquisa deve estar inserida de forma coerente e fecunda no interior das linhas de pesquisa e da(s) área(s) de concentração; ii) a atividade de pesquisa deve ser distribuída de forma coerente e equilibrada pela(s) área(s) de concentração e linhas de pesquisa. As linhas de pesquisa representam agregações da capacidade de pesquisa instalada no programa." Observa-se então que, embora os Cursos de Doutorado tenham a liberdade de estabelecer as temáticas 
científicas mais adequadas com o estado da arte da pesquisa acadêmica-científico-jurídica a partir de suas propostas, elas devem obedecer uma organização interna quanto a essas temáticas e, relembra-se, que estarão sujeitas à aprovação pelos órgãos descritos anteriormente pertencentes ao Sistema Político - Administração, conforme asseverou Luhmann.

4- "É relevante, ainda, que se demonstre a pertinência do novo curso no ambiente local e regional no qual se insere e a sua diferenciação para com os programas já existentes na região, quando for o caso." Este critério é muito importante no que se refere ao que pode ser chamado de função social da pesquisa. Primeiro, fica evidente que não é objetivo da Administração aprovar Cursos que, de certa forma, tenham interesses científico-temáticos semelhantes na mesma região. Isto serve apenas para a organização dos Programas dentro do próprio sistema Político e o que as Políticas de Pesquisa em Direito preveem, posto que, de certa forma, interveem na autonomia científica das Instituições. Ora, se o estado atual da arte do Direito contemporâneo enseja pesquisa científica em determinada área, privilegia-se o Programa que já tenha se consolidado por meio de anterior aprovação de Curso de Mestrado. Na prática, a Instituição de Ensino Superior (IES) que "chegou primeiro" torna-se a detentora da chancela e apoio Estatal para desenvolver investigação científica em determinada temática naquela região. Além de limitar o avanço nas áreas que atualmente carecem de aprofundamento, também se limita a atuação de pesquisadores de outras Instituições em desigualdades estruturais, mas que possuem ótimos requisitos intelectuais, que não podem contribuir com esta mesma área do conhecimento. Este pesquisador, deverá então utilizar-se de sua reputação para encontrar outra Instituição que o acolha. Por sua vez, se este mesmo pesquisador não é oriundo de uma Instituição bem qualificada, terá dificuldades em encontrar tal recepção. Ou seja, ele estará fora do sistema científico por limitações políticas. Esta forma de seleção ou exclusão se encontra em desacordo com o ainda vigente Parecer da CESu $n^{\circ}$ 977/65 cuja política é de ampla formação científica no país possibilitando o aprofundamento científico por parte dos pesquisadores de todas as áreas. Por isso, de acordo com Luhmann (1996), a produção científica embora acoplada com a consciência individual, sempre será uma comunicação que emana do sistema e exteriorizada pelas organizações que efetivamente comunicam. Afinal, as organizações são os únicos subsistemas sociais com capacidade de comunicar ao exterior (output) os resultados elaborados no interior dos sistemas. Os Tribunais 
comunicam as decisões do Direito, as Universidades e Centros de pesquisa comunicam os conhecimentos produzidos cientificamente. E é isso que se vislumbra com a função social da pesquisa, uma forma de output que além de contribuir com a recursividade do Sistema da Ciência, poderá ser observada pelos demais subsistemas sociais.

5- "É recomendável que o Programa ofereça Seminários de Pesquisa para todas as linhas e áreas, além de disciplinas ou seminários que formem um eixo temático, vinculando a(s) área(s) e as linhas de pesquisa." Logo, resta claro que a formação dos novos Doutores, privilegia a capacitação para a pesquisa, mas esta formação dar-se-á a partir de pesquisas que estejam vinculadas às linhas de pesquisa eleitas pelos Programas e aprovadas pela Capes.

6- "Os projetos que concretizam as linhas de pesquisa devem ser preferencialmente coordenados por docentes permanentes e agregar docentes e discentes de modo a evidenciar a sua natureza coletiva. Projetos individuais de um docente permanente, colaborador ou visitante, se existentes, devem ser adequadamente justificados. O projeto de pesquisa deve ser formulado de maneira a que se possa compreender claramente o objeto da investigação, qual a posição da pesquisa no estado do conhecimento sobre o objeto, quais os meios, recursos e propósitos do projeto, bem como quais os resultados pretendidos e mostrar-se adequado à (sic) explicitar as linhas de pesquisa e a área de concentração do programa." A perspectiva de projeto apresentada pela APCN-2017 está em consonância com a visão Luhmanniana acerca das características de projetos de investigação pertinentes ao Sistema da Ciência. Além disso, reforça-se a produção de forma coletiva, a fim de dar consistência às pesquisas desenvolvidas nos Programas o que remete a uma necessária reputação não apenas individual, mas, sobretudo, institucional ou de determinada organização científica.

7- " $50 \%$ da produção do corpo docente permanente deve ter sido publicada em livros (obra única) ou periódicos classificados em A1, A2 e B1.” Aqui se verifica a interface com a questão da produção e publicação das comunicações científicas com base no estrato de qualificação QUALIS CAPES. Sem sombra de dúvidas a exigência de elevada sofisticação intelectual acadêmica deve revelar-se nas publicações dos docentes pesquisadores pertencentes aos Cursos de Doutorado. Por outro lado, a chamada "indústria da produção científica" por Luhmann, acaba legitimando a inclusão e a permanência do docente pesquisador nos quadros de um Curso de Doutorado. Nesse tocante, o Documento de Área2017 (CAPES, 2016c, p.9) admite séria preocupação com os desajustes de exigência de 
produção intelectual: "Como nas duas últimas avaliações, quanto à produção intelectual qualificada, a área fez apenas a consideração da média de pontos entre docentes permanentes, foi incentivada uma verdadeira corrida por pontos."

O principal documento que detalha minuciosamente os critérios avaliativos são os documentos de cada área. A partir de 2016, com a Portaria CAPES nº 40 de 04 de abril artigo $1^{\circ}$, a Avaliação passa a ser quadrienal e será realizada em 2017 referente ao período de 2013 a 2016 e há que se realizar de forma integrada com o Plano Nacional de Pós-Graduação (PNPG), ainda que este trate de todas as áreas do conhecimento enquanto meta até 2020, certamente o Direito, ainda que contendo idiossincrasias no campo da Pós-Graduação e de sua produção do conhecimento, precisa levar em consideração o planejamento orientador da pesquisa. Apesar de o DA-2017 ser mais atual, levar-se-á também em consideração o DA2013, haja vista ser mais completo na descrição dos itens avaliativos e diretrizes e dele não destoar.

De acordo com o DA-2013 constata-se que há uma política para a área do Direito a fim de que sejam renovadas e fortalecidas as pesquisas acadêmicas que se refletem no estímulo aos Programas de Pós-Graduação. Entre as principais diretrizes destacam-se:

3 - articulação da pesquisa científica em Direito, vinculada à melhoria da qualidade
acadêmica e à internacionalização integrada da Área; 4 - discussão sobre possíveis
instrumentos de avaliação da produção acadêmica em formato de livros e capítulos
de livros; 5 - maior integração das pesquisas coletiva do conhecimento e a produção
bibliográfica conjunta; 6 - estímulo às iniciativas conjuntas dos programas de pós-
graduação stricto sensu, buscando a cooperação e a solidariedade interinstitucionais,
especialmente entre programas melhor avaliados e programas novos ou com
necessidade de reestruturação; (CAPES, 2013, p. 3).

Nessas diretrizes é possível observar o indicador forte no sentido de expandir as cooperações internacionais bem como o impacto da pesquisa brasileira no cenário mundial o que está em plena consonância com o PNPG uma vez que, especialmente na área de Ciências Sociais, no período entre 1998 a 2002 o impacto relativo nesta área comparado com o mundo era de - 57, ou seja, negativo, sendo a terceira pior área de impacto internacional das vinte e três consideradas no diagnóstico. (CAPES, 2010, p. 226).

Ressalta-se que a interdisciplinaridade e a coletividade têm papel relevante na pesquisa. Para o DA-2013, a área jurídica é dotada de uma interdisciplinaridade que lhe é intrínseca com qual efetivamente já se concordou antes. O referido documento afirma que as 
áreas de concentração eleitas pelos Programas evidenciam isto notadamente por um visível diálogo entre Política, Economia, Filosofia, História, Literatura, Relações Internacionais, Sociologia e até mesmo com algumas áreas exatas como Física, Química, Medicina e Saúde Coletiva. Portanto, o acadêmico que tem formação em tais programas é demandado por diversas áreas do conhecimento possibilitando uma reflexão jurídica que se enriquece com o saber interdisciplinar. (CAPES, 2013, p. 4). O mesmo é reprisado no DA-2017.

Todavia, é de se ressaltar que a APCN-2017 não contempla em nenhum momento a categoria "interdisciplinaridade" ou similar, deixando então, totalmente ao encargo dos proponentes o envio de propostas nesse sentido a serem avaliadas posteriormente. De fato, para atender a coesão, área de concentração, linhas, projetos, pesquisas, publicações e demais exigências da APCN, o que se constata é uma dificuldade enorme de incluir áreas multi, pluri, inter ou transdisciplinares. Até porque, o aprofundamento teórico-prático sobre determinada área do conhecimento ainda é visto como incompatível com uma observação sob esses pontos de vista, sendo que os pesquisadores que se formaram em Programas interdisciplinares nem sempre conseguem alocar-se nos Programas específicos, suas publicações muitas vezes são mal compreendidas ou até mesmo rechaçadas. Por outro lado, a APCN-2017 (CAPES, 2016b) não proíbe, mas impõe regras para a inclusão de docentes de outras áreas, estabelecendo assim uma limitação de ordem prática para a inserção da interdisciplinaridade.

Nesse tocante, o PNPG reserva um item específico apenas para tratar deste novo contexto (e porque não policontexto) que não se pode deixar de conceber em um mundo de elevada complexidade, como se para observá-la ou até mesmo reduzi-la, apenas uma área específica do conhecimento fosse capaz. Tanto que, dos cinco eixos nos quais se baseia, um deles trata da: “[...] multi- e a interdisciplinaridade entre as principais características da pósgraduação e importantes temas da pesquisa”. Segundo o plano “[...] a CAPES deverá favorecer a realização de encontros científicos envolvendo o segmento como um todo para a discussão dos problemas da Pós-Graduação, bem como das questões associadas à Multi e à Interdisciplinaridade como concepção e processo de produção do conhecimento." (CAPES, 2010, p. 140).

Nas orientações fornecidas pelas fichas a serem utilizadas para a avaliação dos Programas em 2017, observa-se que todos os primeiros cinco critérios referem-se a autoreprodução do Sistema da Ciência e apenas o último diz respeito à prestação que este pode 
oferecer à sociedade evidenciando uma função social, novamente demonstrando o caráter autopoiético do sistema da Ciência que, embora possua relações mais abertas com o meio através das organizações, suas operações denotam em boa medida que, recursivamente, ele comunica cientificamente para comunicar cientificamente. Ou seja, a produção do conhecimento é, sobretudo, para seu próprio uso direto e apenas indiretamente para uma prestação a outros subsistemas.

Conforme o DA-2017 (CAPES, 2016c, p. 12-13), no que se refere à avaliação dos Programas de Doutorado entre todos os focos dos eixos avaliativos, apenas $10 \%$ diz respeito à inserção social e destes, apenas $40 \%$ tratam especificamente da efetiva capacidade de inserção social sob a forma de soluções concretas para o enfrentamento de problemas jurídicos e sociais contemporâneos, reforçando a ideia de autopoiese dantes comentada. Ou seja, boa parte do que se avalia em um Programa de Pós-Graduação em Direito é se ele é capaz de manter a recursividade do sistema da Ciência, sobrevalorando a quantidade de publicações, em especial quando se observa que o foco da produção e divulgação se dá pelo "fluxo" de teses e dissertações.

Logo, há uma avaliação em rede, levando-se em consideração as ingerências qualiquantificativas da própria CAPES no viés produtivo dos Programas. Então, atribuiu-se maior valor à "produção intelectual" em detrimento da própria formação do "corpo discente" e à produção em detrimento da "inserção social”, ainda que o DA-2013 reconheça expressamente que, no futuro, a inserção social deve ser uma dimensão importante. Isto mostra o quanto os Programas de Pós-Graduação em Direito encontram-se defasados em relação a outras áreas do conhecimento que já se encontram em vantajosa inserção social e aproveitamento científico de suas produções pela sociedade.

Nas questões avaliativas do DA-2017 que são quali-quantitativas e que podem direta ou indiretamente influenciar na organização e nas temáticas a serem observadas na produção acadêmico-científica, destacam-se alguns itens que soam interessantes. Os percentuais da avaliação dos Mestrados Acadêmicos e Doutorados estão distribuídos nos seguintes itens e percentuais avaliativos: 1- Proposta do Programa (0\%); 2- Corpo Docente (20\%); 3- Corpo Discente, Teses e Dissertações (30\%); 4- Produção Intelectual (40\%); 5- Inserção Social (10\%). (CAPES, 2016c, p. 9-13). 
O item 1- Proposta do Programa se divide em três esferas: 1.1 Coerência, consistência, abrangência e atualização das áreas de concentração, linhas de pesquisa, projetos em andamento e proposta curricular; (50\%); 1.2 Planejamento do programa com vistas a seu desenvolvimento futuro, contemplando os desafios internacionais da área na produção do conhecimento, seus propósitos na melhor formação de seus alunos, suas metas quanto à inserção social mais rica dos seus egressos, conforme os parâmetros da área (25\%) e 1.3 Infraestrutura para ensino, pesquisa e, se for o caso, extensão (35\%). O item 1.1 se subdivide ainda em mais 5 critérios, basicamente formais, exceto pelo item 3, que avalia a "relevância da temática das disciplinas, dos projetos de pesquisa, das linhas de pesquisa e das áreas de concentração, evitando repetição dos tradicionais 'ramos' do Direito, que desconsidera qualquer problematização ou especificação crítica [...]”. Embora seja apenas um dos cinco, esse deveria ser um item norteador de extrema relevância, porquanto indutor de inovações e de fomento a novas observações dos fenômenos jurídicos, contribuindo com uma efetiva evolução científica na área. Todavia, este item é parte integrante do item maior para o qual se atribui zero por cento. Ou seja, apenas é levado em consideração, mas sem influência direta na avaliação dos Programas. Além disso, ainda que sem o percentual avaliativo, verifica-se que ao item 1.2 que inclui a inserção social são atribuídos apenas $25 \%$ em detrimento de outros 25\% atribuídos à estrutura do Programa. (CAPES, 2016c, p. 9-10).

Seguindo para os itens que efetivamente afetam a avaliação e que estão diretamente relacionados com a produção científica tem-se no item 3 uma subdivisão em 4 itens dos quais 3 são totalmente formais e quantitativos como prazo de defesa de tese, número de teses por orientador, etc. e apenas o item 3.3 trata da "Qualidade das Teses e Dissertações e da produção de discentes autores da pós-graduação e da graduação (no caso de IES com curso de graduação na área) na produção científica do programa, aferida por publicações e outros indicadores pertinentes à área" (CAPES, 2016c, p. 11, grifo nosso) para o qual é atribuído apenas $30 \%$ do total do critério. Todavia, a orientação para a atribuição de nota se dá de novo por um quesito formal e quantitativo, qual seja: "Verificar quanto a proporção da produção intelectual discente representou no cômputo da produção intelectual total do programa.”. Além de ter baixa valoração, o instrumento é incompatível com o objetivo quando se trata de "qualidade" de um lado e de "proporção" e quantidade de outro. 
Conforme o DA-2017 (CAPES, 2016c, p. 11-12), o mesmo se constata no item 4 Produção intelectual que tem peso de $40 \%$ na avaliação total e é subdividido em outros 3 itens dos quais apenas o primeiro trata de "Publicações qualificadas do Programa por docente permanente". Muito embora lhe seja atribuído $40 \%$ do item, tal critério é valorado da seguinte forma: "Calcular o número médio de publicações qualificadas dos programas por docente permanente, valorizando-se, na estratificação, a publicação em estratos mais elevados do qualis e/ou das avaliações de livros." Logo, novamente não há que se falar em qualidade, mas tão somente em cálculos que sobrevaloram a produtividade.

Por fim, no item 5 chamado Inserção Social, igualmente dividido em três subitens, todos eles são deveras relevantes ao se pensar na prestação do Sistema da Ciência e, além disso, possuem uma distribuição percentual bastante adequada:

5.1 Inserção e impacto regional e (ou) nacional do programa (40\%); 5.2 Integração e cooperação com outros programas e centros de pesquisa e desenvolvimento profissional relacionados à área de conhecimento do programa, com vistas ao desenvolvimento da pesquisa e da pós-graduação (40\%); 5.3. Visibilidade e transparência dada pelo programa à sua atuação (20\%).(CAPES, 2016c, p.12-13).

Entretanto, o item inserção social todo contribui apenas com $10 \%$ da avaliação do Programa evidenciando um descompasso com o PNPG, mas, por outro lado, reforçando a recursividade da Ciência. De fato, muito embora não seja o foco desta pesquisa, parece haver uma clara intenção por parte das organizações de pesquisa uma divisão entre o estritamente acadêmico e o acadêmico com reflexos práticos na sociedade. Isso fica claro com avaliação realizada com os Mestrados Profissionais, na qual se destacam prioritariamente a inserção social dos futuros profissionais e das pesquisas produzidas.

\section{CONCLUSÃO}

A pesquisa observou a interferência do Sistema da Política na produção acadêmicocientífica sobre o Direito avaliando como as organizações de pesquisa no Brasil podem afetar tais comunicações propiciadas pelos Programas de Pós-Graduação Stricto Sensu em Direito (nível de Doutorado). Tal análise realizou-se com base nos preceitos Constitucionais de fomento à pesquisa e desenvolvimento científico. Tendo em vista que o escopo desta pesquisa foi identificar como as Políticas de Pós-Graduação em Direito podem afetar tais 
interferências, passa-se a destacar alguns aspectos das irritações a partir do campo das organizações mais relevantes aqui apresentadas.

A partir da análise organizacional da pesquisa científica no Brasil, incluindo as principais organizações que influenciam direta e indiretamente no que se produz cientificamente na área do Direito, bem como nos PPGD's, restou claro que o acoplamento do Sistema da Ciência com o Sistema da Política interfere sobremaneira no modus operandi dos PPGD's e nas operações da Ciência no que se refere às publicações científicas. Nem poderia ser diferente, pois, admitindo-se a policontexturalidade como condição de observação social, os subsistemas se multiplicam, as relações se complexificam e as organizações se sofisticam com intuito de dar conta desta complexidade. Elas produzem, por consequência, mais complexidade relacional que precisam ser consideradas.

Ainda que a autopoiese do Sistema da Ciência se preserve, com todas as características que lhe são inerentes, as organizações como a CAPES, o MEC e o MCTI são inerentes ao Sistema da Política. Portanto, refletem as expectativas do Estado com a vinculação de suas políticas públicas referentes à pesquisa e à Pós-Graduação no país. Veja-se que o impacto causado pelo Sistema da Política é alto. Ainda que a CAPES seja uma organização em acoplamento com o Sistema da Ciência e da Educação suas decisões políticas afetam sobremaneira o Sistema da Ciência. Ela utiliza seus diagnósticos e resultados para a formulação tanto de políticas para a Pós-Graduação quanto para a concessão de bolsas e auxílios financeiros para a pesquisa. Assim, verifica-se que não só a avaliação é realizada pela CAPES, como também por meio dela há regulação e direcionamento com as Políticas Públicas para a pesquisa no país.

Nesse tocante, chamaram atenção algumas convergências e incompatibilidades internas entre o PNPG proposto para até 2020, a APCN-2017 cuja aprovação final será decidida pelo Conselho Nacional de Educação e o DA do Direito (2013 e 2016) que avalia os Programas.

Interessante destacar que, de acordo com a composição do Conselho Superior, há uma demonstração da enorme quantidade de relações com outras organizações oriundas tanto do sistema da Ciência, quanto da Educação, da Política e até mesmo da Economia, como se verifica com a participação de membros do setor empresarial, voltadas para os processos de decisão da CAPES e que definem e regulamentam as políticas da Pós-Graduação no país. 
Viu-se que, mesmo com a representatividade dos Programas de Pós-Graduação e das instituições científicas, do maior nível acadêmico das áreas, as decisões da CAPES são primordialmente políticas, posto que tais organizações assumem com grau de prioridade a função do sistema ao qual pertencem. Isso denota que, em que pese o sistema da Ciência ser um sistema autopoiético, dotado de recursividade e que, embora as produções acadêmicocientíficas chamadas teses sejam incluídas como comunicações deste sistema, há sim, uma interferência nas suas operações, o que também afeta direta ou indiretamente nas escolhas temáticas sobre as quais se produz conhecimento sobre o Direito e sobre como essa comunicação será feita. Logo, sua capacidade de interferência na Dogmática também sofre irritações dos demais Sistemas que não só o da Ciência.

Apesar de haver enredada forma de representatividade dos PPGD's nestes órgãos por meio dos Coordenadores de área, em especial na CAPES, constatou-se que, atualmente, esta representação se mostra desproporcional ao número de Programas e regiões nas quais são ofertados. Isso não é compatível com a perspectiva da APCN-2017 que considera relevante a pertinência dos novos cursos a partir do ambiente local e regional no qual se insere. Isto pode interferir tanto na abertura quanto na avaliação dos PPGD's. Portanto, carece de reflexão a forma de representação acadêmico-científica na CAPES. Nesse sentido, o papel dos Coordenadores de área representa um importante elo entre os Sistemas e sua atuação pode estabelecer melhores acoplamentos entre as organizações envolvidas.

Outro item que se mostra incongruente na organização é a questão da interdisciplinaridade da pesquisa em Direito. Para Luhmann, o Sistema da Ciência deve valerse deste recurso, sendo até mesmo salutar para que uma observação seja realizada com sofisticação. O mesmo é reforçado pelo DA do Direito, sugerindo que a interdisciplinaridade chega a ser intrínseca ao fenômeno jurídico. Entretanto, em nenhum momento da APCN2017 há menção à interdisciplinaridade. Não bastasse isso, em que pese não haver proibição de inclusão de docentes nos PPGD’s que sejam de outras áreas, há limitações. Na prática, essa interdisciplinaridade dos PPGD's não se evidencia assim tão claramente.

De fato, para atender a coesão, área de concentração, linhas, projetos, pesquisas, publicações e demais exigências da APCN, o que se constata é uma dificuldade enorme de incluir áreas multi, pluri, inter ou transdisciplinares. 
Já para o PNPG, quando se dá destaque às temáticas multi e interdisciplinares, o que se faz é reconhecer a importância crescente de segmentos do conhecimento e da pesquisa que, em razão da sua dinâmica interna e complexidade incessante, exige a conjugação de diversas metodologias e conceitos disciplinares para que se possa enfrentar os diversos problemas. Embora isso seja um desafio para a Pós-Graduação, considera-se que o PNPG tenha condições de municiar os PPGD’s com instrumentos e mecanismos apropriados para esta nova perspectiva. Isso exigirá reformulação institucional, organizacional e a inclusão de novas parcerias para além das fronteiras disciplinares. Nesse sentido, deve prevalecer a ideia de que Programas dotados destas características, no futuro não poderão prescindir do que hoje se classificam como grandes áreas multidisciplinares. É o que ocorre em outros países como na Alemanha e nos EUA com a busca da excelência e do conhecimento inovador passando pelas abordagens e práticas multi e interdisciplinares. Segundo o PNPG o Brasil deve preparar-se para dar esse salto.

Do ponto de vista do impacto e da capacidade de irritação intersistêmica das pesquisas em Direito, ganha destaque a recomendação feita para as produções coletivas. Isso aparece explicitamente na APCN-2017. Lá, consta que os projetos que devem concretizar as linhas de pesquisa precisam agregar docentes permanentes e discentes de modo que se evidencie a natureza coletiva dos projetos. Esta perspectiva está em consonância com o que Luhmann assevera acerca das características de projetos de investigação pertinentes ao Sistema da Ciência. Reforça-se a produção de forma coletiva a fim de dar consistência às pesquisas desenvolvidas nos Programas o que remete a uma necessária reputação não apenas individual, mas, sobretudo, institucional ou de determinada organização científica.

Veja-se que estas indicações parecem acertadas se existe o objetivo de inserção social ou possibilidade de aproveitamento concreto das produções acadêmico-científicas em Direito para o meio ou para os demais sistemas. Afinal, quanto maior a reputação e credibilidade, que é conseguida sempre mais facilmente por meio das organizações e não dos esforços individuais, maior a possibilidade de fixação das pesquisas e consequente ressonância, em especial na Dogmática jurídica.

Hoje, as parcerias entre os PPGD’s nacional ou internacionalmente são estimuladas, até porque é difícil pensar que um programa sozinho consiga se destacar com tamanho alcance de interferência. Embora isso possa se relativizar, eventualmente, uma pesquisa 
isolada dificilmente conseguirá credibilidade e reputação suficiente para provocar irritação em meio a tanta oferta de publicação científica (variação). De fato, como os pesquisadores individuais não gozam, via de regra, de tamanha reputação o que se precisa fortalecer são os grupos. E para isso, não é suficiente, por exemplo, fazer publicações com alguns textos individuais em forma de coletânea, pois ainda assim serão publicações individuais. É preciso coletivizar pesquisas de alto impacto para aumentar a reputação e credibilidade. Grandes projetos, e posteriores grandes parcerias, leva tempo. Mas é preciso reconhecer as limitações da individualidade que muitas vezes serve apenas para permitir a inserção do futuro doutor formalmente no Sistema da Ciência. Isso também é um desafio, porquanto raramente se encontra predisposição para o trabalho coletivo. Veja-se, as teses são provações da capacidade intelectiva individual do futuro doutor. Se ao longo de tantos anos manteve-se isolado, como exigir dele habilidades para produção coletiva posterior. Os PPGD's não privilegiam a produção coletiva, mas insiste-se, tanto do ponto de vista teórico de viés sistêmico, quanto do ponto de vista organizacional da pesquisa, demonstrou-se que essas comunicações científicas têm mais capacidade de ressonância.

Da análise dos documentos principais que norteiam a aprovação e a avaliação da Pós-Graduação no país, constatou-se que se reforça constantemente o caráter autopoiético e reprodutivo do Sistema da Ciência. Ou seja, produz-se, publica-se e divulga-se para o aprimoramento essencial da própria pesquisa, para a divulgação e discussão entre pares, deixando a prestação do Sistema da Ciência (inserção social) em último plano. Veja-se que a difusão do conhecimento jurídico a fim de viabilizar a concretização dos direitos dos cidadãos aparece apenas no último item do DA-2013 e no DA-2017 não há qualquer menção neste sentido.

Observa-se assim, que os demais objetivos referem-se à auto-reprodução do Sistema da Ciência e apenas um deles diz respeito à prestação que este pode oferecer à sociedade evidenciando o caráter social da pesquisa. O que se constatou, é que, embora o Sistema da Ciência possua relações mais abertas com o meio através das organizações, suas operações denotam em boa medida que ele comunica cientificamente para voltar a comunicar cientificamente, mesmo que isso evidencie um novo conhecimento. Ou seja, a produção do conhecimento é, sobretudo, para seu próprio uso e apenas indiretamente para uma prestação a outros subsistemas. 
Nesse tocante, é que se chama a atenção para o aproveitamento das teses sobre o Direito, porquanto disputam espaço de crédito e confiabilidade com a própria Dogmática (auto-observação do Direito). É claro que o Direito mantém sua autopoiese e com isso, é mais evidente que suas decisões sejam pautadas em seus elementos internos reproduzindo, pois, Dogmática. Todavia, o que se pode vislumbrar é que uma produção acadêmico-científica chancelada pelos Programas de Pós-Graduação em Direito com maior qualidade e mais voltada para a inserção social e com maior capacidade de interferência na Dogmática possa vir a servir mais para a prestação do Sistema da Ciência do que eminentemente para a sua autopoiese. Para tanto, há que se ajustar tanto Política Pública proposta pelas organizações sob comento quanto suas comunicações (documentos) orientativos e reguladores, porquanto se mostram incongruentes em muitos aspectos.

\section{REFERÊECIAS:}

ARNOLD-CATHALIFAUD, Marcelo. Imágenes de la complejidad: La organización de las organizaciones. In: ARNOLD-CATHALIFAUD, Marcelo; CADENAS, Hugo; URQUIZA, Anahí. La Organización de las organizaciones sociales: Aplicaciones desde perspectivas sistêmicas. Santiago: RIL Editores, 2014.

BRASIL. Constituição da República Federetiva do Brasil, de 5 de outubro de 1988. Disponível em: < http://www.planalto.gov.br/ccivil_03/constituicao/constituicaocompilado.htm>. Acesso em: 12 out. jun. 2017

BRASIL. Lei. $N^{o}$ 7.692, de 02 de março de 2012. Aprova o Estatuto e o Quadro Demonstrativo dos Cargos em Comissão da Coordenação de Aperfeiçoamento de Pessoal de Nível Superior - CAPES, e remaneja cargos em comissão. Disponível em:〈http://www.planalto.gov.br/ccivil_03/_Ato2011-2014/2012/Decreto/D7692.htm\#art5.>

Acesso em: 28 abr. 2017.

COORDENAÇÃO DE APERFEIÇOAMENTO DE PESSOAL DE NÍVEL SUPERIOR. Parecer/CESU $\quad \mathbf{n}^{\mathbf{0}} \quad \mathbf{9 7 7 / 1 9 6 5}$ Disponível em:< https://www.capes.gov.br/images/stories/download/legislacao/Parecer_CESU_977_1965.pdf> Acesso em 08 fev. 2017.

COORDENAÇÃO DE APERFEIÇOAMENTO DE PESSOAL DE NÍVEL SUPERIOR. Competências. Disponível em: <http://www.capes.gov.br/acessoainformacao/80-conteudoestatico/acesso-a-informacao/5418-competencias>. Acesso em 8 fev. 2017. 
COORDENAÇÃO DE APERFEIÇOAMENTO DE PESSOAL DE NÍVEL SUPERIOR. Coordenadores de Áreas. Disponível em: http://www.capes.gov.br/component/content/article/44-avaliacao/4663-direito. Acesso em: 10 de jun. 2017.

COORDENAÇÃO DE APERFEIÇOAMENTO DE PESSOAL DE NÍVEL SUPERIOR. Etapas da Avaliação de Propostas de Novos Cursos. Disponível em: < http://www.capes.gov.br/avaliacao/entrada-no-snpg-propostas/91-conteudoestatico/avaliacao-capes/6829-etapas-da-avaliacao-de-propostas-de-cursos-novos>. Acesso em: 19 jun. 2017.

COORDENAÇÃO DE APERFEIÇOAMENTO DE PESSOAL DE NÍVEL SUPERIOR. Documento de Área. Direito 2013. Brasília, 2013. 45 p. Disponível em: < https://www.capes.gov.br/images/stories/download/avaliacaotrienal/Docs_de_area/Direito_do c_area_e_comiss\%C3\%A3o_16out.pdf>. Acesso em: 08 fev. 2017.

COORDENAÇÃO DE APERFEIÇOAMENTO DE PESSOAL DE NÍVEL SUPERIOR. Portaria n n $^{\mathbf{9}}$ de 29 julho de 2015. Disponível em: < http://www.capes.gov.br/images/stories/download/avaliacao/avaliacao-n/Portaria-capes-9091-2015.pdf>. Acesso em: 08 fev. 2017.

COORDENAÇÃO DE APERFEIÇOAMENTO DE PESSOAL DE NÍVEL SUPERIOR. Portaria $\mathrm{n}^{\mathbf{0}} \mathbf{4 0}$ de $\mathbf{0 4}$ abril de 2016. Disponível em: < https://www.capes.gov.br/images/stories/download/legislacao/15042016-Portaria-46Regulamento-PIBID-completa.pdf >. Acesso em: 08 fev. 2017.

COORDENAÇÃO DE APERFEIÇOAMENTO DE PESSOAL DE NÍVEL SUPERIOR. Apresentação de Propostas de Cursos Novos - APCN 2016 - Direito. Brasília, 2016a. 17p. Disponível em:

http://www.capes.gov.br/images/documentos/Criterios_apcn_2016/Criterios_APCN_Direito.p df $>$. Acesso em 20 abr. 2017.

COORDENAÇÃO DE APERFEIÇOAMENTO DE PESSOAL DE NÍVEL SUPERIOR. Apresentação de Propostas de Cursos Novos - APCN 2017 - Direito. Brasília, 2016b. 20 p.

Disponível em:

http://www.capes.gov.br/images/documentos/Criterios_apcn_2semestre/Crit\%C3\%A9rios_de _APCN_2017_-_Direito.pdf>. Acesso em 20 abr. 2017.

COORDENAÇÃO DE APERFEIÇOAMENTO DE PESSOAL DE NÍVEL SUPERIOR. Documento de Área. Direito 2017. Brasília, 2016c. 22 p. Disponível em: < http://www.capes.gov.br/images/documentos/Documentos_de_area_2017/26_DIRE_docarea_ 2016.pdf > . Acesso em: 05 maio 2017.

COORDENAÇÃO DE APERFEIÇOAMENTO DE PESSOAL DE NÍVEL SUPERIOR. Plano Nacional de Pós-Graduação - PNPG 2011-2020.v.1. Brasília: CAPES, 2010, 
Disponível em: $<$ http://www.capes.gov.br/images/stories/download/Livros-PNPG-Volume-IMont.pdf >. Acesso em: 08 fev. 2017.

CORSI; ESPOSITO, Elena; BARALDI, Claudio. Glosario sobre la teoria social de Niklas Luhmann. México: Universidad Iberoamericana,1996.

KATO, Fabíola Grello. Por um novo paradigma científico? Políticas de Estado e financiamento de pesquisas. Revista de Educação Unisinos. São Leopoldo, v.16, n.2, p. 169178, 2012. Disponível em:

http://www.unisinos.br/revistas/index.php/educacao/article/view/edu.2012.162.09/972>

Acesso em: 10 jan. 2017.

LUHMANN, Niklas. La Ciencia de la Sociedad. Trad. Silvia Pappe, B. Erker e Luis Segura sob Coord. Javier Nafarrate. México: Universidad Iberoamericana, 1996.

LUHMAnN, Niklas. Teoría Política en el estado de Bienestar. Madrid: Alianza Editorial, 2002.

LUHMANN. La sociedad de la sociedad. Trad. Javier Nafarrate. México: Herder, 2007.

LUHMANN, Niklas. Introdução à teoria dos sistemas. Tradução de Ana Cristina Arantes Nasser. 2.ed. Petrópolis: Vozes, 2010a.

LUHMANN, Niklas. Organización y Decisión. Tradução de Darío Rodríguez Mansilla. México: Universidad Iberoamericana, 2010b.

MANSILLA, Darío Rodríguez. Gestión Organizacional: Elementos para su estúdio. 3.ed., Chile: Ediciones Universidad Católica de Chile, 2004.

STICHWEH, Rudolf. Science in the system of world society. Social Science Information (SSI), Paris, n. 35, v.2, p. 327-340, june 1996. Disponível em: $<$ http://ssi.sagepub.com/content/35/2.toc $>$. Acesso em: 02 fev. 2017.

Recebido em: 20 de julho de 2017.

Aceito em : 27 de julho de 2017. 